\title{
Iodine transfer from agricultural soils to edible part of crops
}

\author{
By S. Uchida* and K. Tagami \\ Office of Biospheric Assessment for Waste Disposal, National Institute of Radiological Sciences, Anagawa 4-9-1, Inage-ku, Chiba 263-8555, \\ Japan
}

(Received November 26, 2009; accepted in revised form November 11, 2010)

\section{Iodine / Transfer factor / Agricultural soil / Crop / ${ }^{129} \mathrm{I} /$ Bromine}

Summary. Information about the distribution and cycling of stable iodine (I) in the environment is useful for dose estimation from its long-lived radioiodisotpe, ${ }^{129} \mathrm{I}$, which is one of the most critical radionuclides to be managed for the safe disposal of nuclear fuel waste. The soil-to-plant transfer factor (TF) is an important parameter to predict internal radiation exposure pathways through the food chains using mathematical models. Therefore, we have measured stable I and bromine $(\mathrm{Br})$ for comparison, in 142 crop samples and associated agricultural field soil samples collected throughout Japan. The crops were classified into eight groups, i.e. leafy vegetables, white part of leeks, fruit vegetables, tubers, root crops, legumes, wheat and barley (WB), and rice. The results showed that $\mathrm{Br}$ and $\mathrm{I}$ concentrations were higher in upland field soil samples than in paddy field soil samples. However, when we compared TF values of $\mathrm{WB}$ and brown rice, no statistical difference was observed. The highest geometric mean of TF for I, $1.4 \times 10^{-2}$, was obtained for leafy vegetables and fruit vegetables and that for $\mathrm{Br}, 1.5$, was for fruit vegetables. TF for I was much lower than $\mathrm{Br}$, as reported previously, maybe due to their different chemcial forms in soil and uptake behaviors by plant roots.

\section{Introduction}

Iodine (I) behavior is of interest because its very long-lived isotope ${ }^{129} \mathrm{I}$ (half life: $1.57 \times 10^{7} \mathrm{y}$ ) is often the most limiting and critical radionuclide in both transuranic and high level radioactive waste management due to its high mobility in the terrestrial environment. Since stable I can be used as a natural analogue of ${ }^{129} \mathrm{I}$, information about the distribution and cycling of stable I in the environment is highly useful for estimating the dose from ${ }^{129} \mathrm{I}$.

To predict internal radiation exposure pathways through food, mathematical models have been used and environmental transfer parameters have been applied in these models. The soil-to-plant transfer factor (TF) is an important parameter because a significant exposure pathway to humans is ingestion of contaminated food. Recently, the IAEA compiled TFs of I in several crops collected in temperate areas [1]. However, number of available data sets were still limited; for example, only one value for tubers

\footnotetext{
*Author for correspondence (E-mail: s_uchida@nirs.go.jp).
}

and fruit vegetable was given since data were only collected from radiotracer experiments. Sheppard et al. [2] recently provided concentration ratio data which are analogous to TF data; however, only one value for human foods, 0.005 was given. This is problematic, since it has been reported previously that TF values of I change for different crops $[3,4]$.

In Japan, several TF data have been reported for stable I [5-8], but the data were not collected from all over the country so that it is not clear whether such data could be generic for Japan or not. In this study, therefore, we measured I concentrations in 142 crop samples and associated agricultural field soil samples collected throughout Japan to supply more TF data.

\section{Experimental}

\subsection{Samples}

Surface layer $(0-20 \mathrm{~cm})$ soil samples from 79 upland fields and 63 paddy fields were collected nationwide in Japan from 2002 to 2006 during the harvesting season. Soils were classified as Fluvisols (77 sites), Andosols (35 sites), Cambisols (27 sites), and other soil types (5 sites) according to FAO/UNESCO soil taxonomy [9].

Edible parts from crops grown in these agricultural fields were also collected in the harvesting season. For 4 leek plants, green and white parts were separated as individual samples. For Japanese radish and carrot samples, leaves are also edible parts so that the roots and leaves were separated and elemental compositions were measured for both parts in one sample of each crop. Numbers of samples were; leafy vegetables, 22 ( 7 cabbage, 4 Chinese cabbage, 4 leek (green part), 2 lettuce, 2 spinach, 1 Nozawana, 1 Japanese radish, and 1 carrot); root crops, 14 (7 Japanese radish, 4 onion, and 3 carrot); tubers, 11 (6 potato, 3 sweet potato, and 2 taro); fruit vegetables, 18 (6 tomato, 5 egg plant, 4 cucumber, 2 green pepper, and 1 bitter cucumber); legumes, 7 (6 soybean and 1 peanut); cereals except rice, 9 ( 7 wheat and 2 barley); and rice, 63 (brown rice, white rice, and bran). Since the white part of leeks is grown underground, whether to classify it as a leafy vegetable or a root vegetable is unclear. Then, we classed the white part of leeks separately as its own group with 4 samples. In total, 148 crop part samples together with the associated soil samples were used in this analysis. 


\subsection{Measurements}

A simple extraction method was applied to measure stable I and $\mathrm{Br}$ in plant samples by inductively coupled plasma mass spectrometry (ICP-MS) [10]. About $100 \mathrm{mg}$ of dried-sample were weighed into a $6 \mathrm{~mL}$ PFA vessel (026R, Savillex Co.). Then, $1 \mathrm{~mL}$ of super-pure grade $25 \%$ tetramethyl ammonium hydroxide, TMAH (TAMAPURE-AA-100, Tama Chemicals Co. Ltd.), was added and the vessel was closed tightly. The vessel was heated over night (about $12 \mathrm{~h}$ ) at $60^{\circ} \mathrm{C}$. The sample was diluted to $50 \mathrm{~mL}$ with deionised water and centrifuged to obtain supernatant which contained about $0.5 \%$ TMAH for iodine measurement by ICP-MS. The method can successively recover $c a .100 \%$ of I from plant samples [10]. The same method is also applicable to $\mathrm{Br}$ concentration measurements.

For soil samples, energy dispersive X-ray fluorescence (Epsilon 5, PANalytical B. V.) was used as described before [11]. In brief, about $10 \mathrm{~g}$ amount of each soil sample were powdered and pressed into a 32-mm diameter pellet using a hydraulic press operated at 20 tons pressure. The Compton-scattered line was used as an internal standard to compensate for variations in sample matrix, particle size, packing density, and instrumental operating characteristics.

\section{Results and discussion}

Total $\mathrm{Br}$ and I concentrations in different agricultural uses, i.e., upland fields and paddy fields, were compared and the results are shown in Fig. 1. Concentrations of $\mathrm{Br}$ and I were statistically higher $(t$-test, $p<0.001)$ in upland fields than in paddy fields. The resultsagreed well with previously reported ones $[6,12]$, while, the variations in $\mathrm{Br}$ and I concentrations observed in upland fields and paddy fields were due to different redox conditions.

In order to know which soil group contained the highest $\mathrm{Br}$ and/or I concentration, we compared the soil samples as shown in Fig. 2, and the geometric means (GMs) and ranges for four soil groups are listed in Table 1. Concentrations of Br inAndosol samples (GM: $31.8 \mathrm{mg} \mathrm{kg}^{-1}$ ) collected in upland fields were significantly higher than in samples of other soil groups except for the Andosol samples collected in paddy fields. However, among soil groups excluding An-
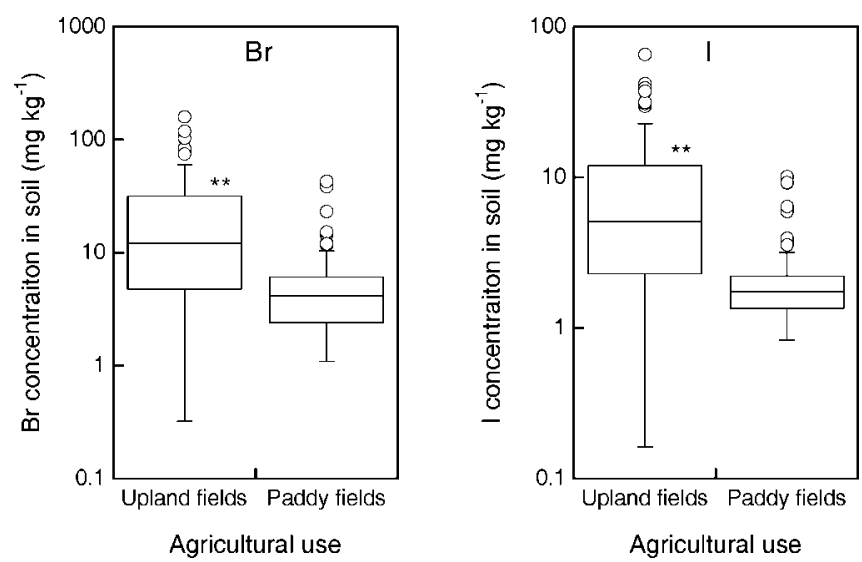

Fig. 1. Box-and-whisker plot of Br (left) and I (right) concentrations in upland and paddy fields. Asterisks (**) show the statistical difference $(p<0.001)$ by $t$-test.
Table 1. Geometric means (GMs) and ranges of $\mathrm{Br}$ and I concentrations in four soil groups for samples collected in upland and paddy fields on a dry weight basis.

\begin{tabular}{|c|c|c|c|c|c|}
\hline \multirow[t]{2}{*}{ Soil group } & \multirow[t]{2}{*}{$N$} & \multicolumn{2}{|c|}{ Bromine $\left(\mathrm{mg} \mathrm{kg}^{-1}\right)$} & \multicolumn{2}{|c|}{ Iodine $\left(\mathrm{mg} \mathrm{kg}^{-1}\right)$} \\
\hline & & GM & $\begin{array}{c}\text { Range } \\
(\min -\max )\end{array}$ & GM & $\begin{array}{c}\text { Range } \\
(\min -\max )\end{array}$ \\
\hline \multicolumn{6}{|c|}{ Upland fields } \\
\hline Andosol & 29 & 31.8 & $5.5-158$ & 11.8 & $1.8-65.5$ \\
\hline Fluvisol & 31 & 6.3 & $1.6-80.7$ & 3.0 & $1.3-37.4$ \\
\hline Cambisol & 19 & 7.3 & $2.0-34.1$ & 4.2 & $0.8-19.9$ \\
\hline Other & 2 & $11.6^{*}$ & $0.3-22.9$ & $11.5^{*}$ & $0.2-22.8$ \\
\hline \multicolumn{6}{|c|}{ Paddy fields } \\
\hline Andosol & 6 & 12.8 & $4.0-42.7$ & 3.8 & $1.1-10.1$ \\
\hline Fluvisol & 46 & 3.8 & $1.1-15.3$ & 1.8 & $0.8-9.3$ \\
\hline Cambisol & 8 & 3.2 & $1.6-5.9$ & 1.7 & $1.2-2.8$ \\
\hline Other & 3 & 8.7 & $6.3-12.0$ & 3.4 & $2.8-3.7$ \\
\hline
\end{tabular}
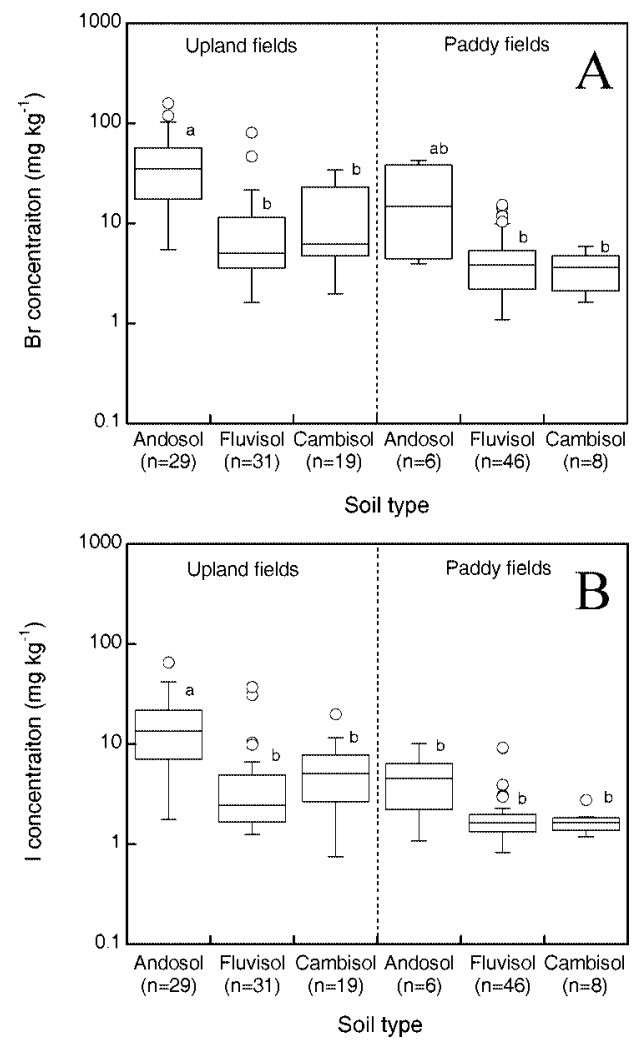

Fig. 2. Box-and-whisker plot of $\mathrm{Br}$ (a) and I (b) concentrations in Andosol, Fluvisol, and Cambisol samples collected in upland and paddy fields. Number of samples $n$ is given for each soil groups. The data followed by the same letter are not significantly different $(p<0.05)$.

dosol collected in upland fields there were no differences. For I, Andosol samples collected in upland fields (GM: $11.8 \mathrm{mg} \mathrm{kg}^{-1}$ ) had results that were different from other soil groups. GMs of $\mathrm{Br}$ and I excluding Andosol samples collected from upland fields were $5.0 \mathrm{mg} \mathrm{kg}^{-1}$ and $2.4 \mathrm{mg} \mathrm{kg}^{-1}$, respectively. The higher $\mathrm{Br}$ and I concentrations in upland fields were due to the characteristics of Andosol. Muramatsu and Yoshida [12] also reported that I concentrations were high in Andosol.

It was difficult to check the effect of concentration differences in upland fields and paddy fields for $\mathrm{Br}$ and I con- 

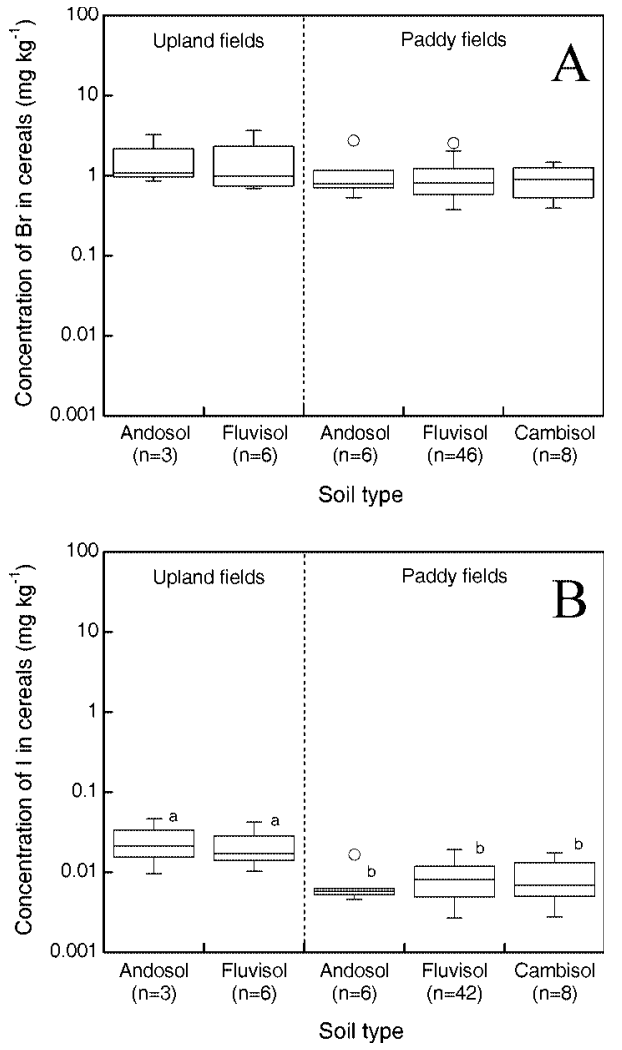

Fig. 3. Box-and-whisker plot of $\mathrm{Br}$ (a) and I (b) concentrations in wheat and barely for upland fields, and brown rice in paddy fields for each soil group. Number of cereal samples $n$ is given for each soil groups. The data in the right graph followed by the same letter are not significantly different $(p<0.05)$.

centrations in crops if we used all the crop samples. Thus we used $\mathrm{Br}$ and I concentration data for wheat and barley (WB) collected in upland fields for comparison with data for brown rice collected in paddy fields. The WB samples were only hulled, thus the data would be comparable to those for brown rice; besides, these crops are in the same plant family, Poaceae. As shown in Fig. 3, for Br, no concentration differences were observed for all soil groups, however, for I, the concentrations were higher in soil groups collected in upland fields than in paddy fields. GMs of $\mathrm{Br}$ in $\mathrm{WB}$ and brown rice were 1.3 and $0.86 \mathrm{mg} \mathrm{kg}^{-1}$ dry, respectively $(p>0.05)$, and those of I were 0.020 and $0.0077 \mathrm{mg} \mathrm{kg}^{-1}$ dry, respectively $(p<0.05)$. From this result, we concluded that I concentrations in crops were not related to soil groups but rather to agricultural uses and/or crop species.

Since the main source of $\mathrm{Br}$ and I is seawater, their correlations were also compared in soil and crop samples (Fig. 4) to elucidate how these elements went from the sea through the terrestrial environment. In upland fields and paddy fields, $\mathrm{Br}$ and I concentrations were close to a log-normal distribution, thus, logarithms of the data were chosen for statistical analysis. In both agricultural uses, $\mathrm{Br}$ and I were well correlated, i.e., the correlation coefficients were $0.89(p<0.001)$ for upland fields and $0.76(p<0.001)$ for paddy fields by $t$-test. However, when we compared $\mathrm{Br}$ and I concentrations in WB and brown rice, no correlation was observed. Thus, we concluded that chemical forms of $\mathrm{Br}$ and $\mathrm{I}$ in soil and $\mathrm{Br}$ and I uptake mechanisms by plant roots would be different.
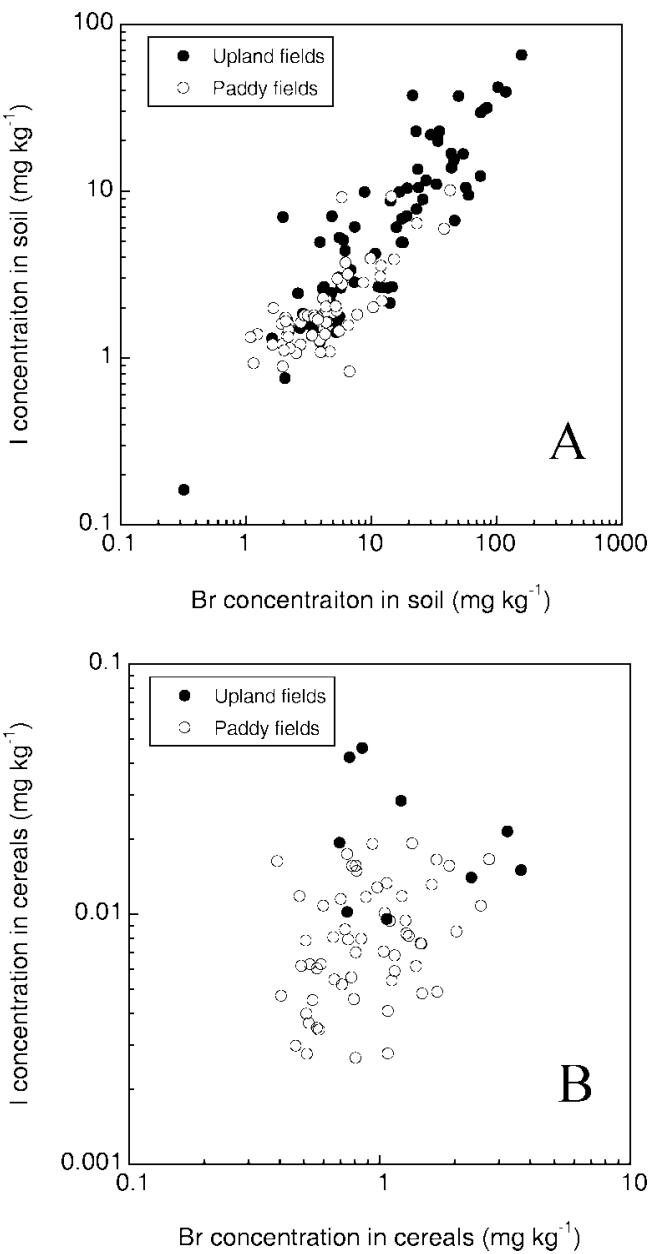

Fig. 4. Correlations between $\mathrm{Br}$ and I concentrations in soil samples (a) and cereals (wheat and barley for upland fields and brown rice for paddy fields) (b)

Using the 148 data sets, we calculated TF values. The $\mathrm{TF}$ is defined as the plant/soil concentration ratio (on dry weight basis), and the results are listed in Table 2. The GM of TFs of I for fruit vegetables and leafy vegetables, $1.4 \times 10^{-2}$, was the highest among the crops, while the lowest value of $3.9 \times 10^{-3}$ was obtained for brown rice samples. The TFs for brown rice were within the previously reported values, $1.5 \times 10^{-4}$ to $3.9 \times 10^{-2}[1,5,6]$. The TFs of $I$ for the white part of leeks were within the range of leafy vegetables, however, the GM value was much closer to that of root crops. The GM for each crop group in the present study were almost the same as previously reported values of radiotracer experiments collected worldwide and in Japan [1,37]. The GMs of tubers and fruit vegetables compiled by the IAEA [1] were, however, 1-2 orders of magnitude higher. The GM of TFs of I for WB were about 8 times higher than that for cereals compiled by the IAEA, which may be due to greater I mobility in the Japanese agricultural soil samples.

For $\mathrm{Br}$, the highest GM of TFs was obtained for fruit vegetables, 1.5 , and the lowest value was 0.16 for WB samples. For all crop groups, GMs of TFs of Br were 2 orders of magnitude higher than those of I. Yuita et al. [6] reported about a 40 times higher TF value for $\mathrm{Br}$ than that for I in wild plants. Thus, we observed the same tendency for crops. For the case of I, direct deposition onto plant surfaces would be negligible [8]; however, for $\mathrm{Br}$, this phenomenon has not 
Table 2. Soil to crop (edible part) transfer factors.

\begin{tabular}{|c|c|c|c|}
\hline Crop parts & $\begin{array}{l}\text { Bromine } \\
\text { Geometric mean, } \\
\text { number of data } \\
(\min -\max )\end{array}$ & $\begin{array}{c}\text { Iodine } \\
\text { Geometric mean, } \\
\text { number of data } \\
(\min -\max )\end{array}$ & Ref. \\
\hline Leafy vegetables & $\begin{array}{c}1.0, n=22 \\
\left(9.5 \times 10^{-2}-1.4 \times 10^{1}\right)\end{array}$ & $\begin{array}{c}1.4 \times 10^{-2}, n=22 \\
\left(9.8 \times 10^{-4}-4.9 \times 10^{-1}\right)\end{array}$ & This study \\
\hline Leafy vegetables & & $\begin{array}{c}6.5 \times 10^{-3}, n=12 \\
\left(1.1 \times 10^{-3}-1.0 \times 10^{-1}\right)\end{array}$ & {$[1]$} \\
\hline Leek (white part) & $\begin{array}{c}1.9 \times 10^{-1}, n=4 \\
\left(7.6 \times 10^{-2}-3.1 \times 10^{-1}\right)\end{array}$ & $\begin{array}{c}4.0 \times 10^{-3}, n=4 \\
\left(1.3 \times 10^{-3}-8.4 \times 10^{-3}\right)\end{array}$ & This study \\
\hline Root crops & $\begin{array}{c}6.7 \times 10^{-1}, n=14 \\
\left(1.1 \times 10^{-1}-2.6 \times 10^{0}\right)\end{array}$ & $\begin{array}{c}6.1 \times 10^{-3}, n=14 \\
\left(8.7 \times 10^{-4}-6.7 \times 10^{-2}\right)\end{array}$ & This study \\
\hline Root crops & & $\begin{array}{c}7.7 \times 10^{-3}, n=28 \\
\left(1.4 \times 10^{-3}-4.7 \times 10^{-2}\right)\end{array}$ & {$[1]$} \\
\hline Tubers & $\begin{array}{c}7.7 \times 10^{-1}, n=11 \\
\left(1.1 \times 10^{-1}-1.2 \times 10^{1}\right)\end{array}$ & $\begin{array}{c}6.9 \times 10^{-3}, n=11 \\
\left(9.4 \times 10^{-4}-9.4 \times 10^{-2}\right)\end{array}$ & This study \\
\hline Tubers & & $1.0 \times 10^{-1}, n=1$ & {$[1]$} \\
\hline Fruit vegetables & $\begin{array}{c}1.5 \times 10^{0}, n=18 \\
\left(7.8 \times 10^{-2}-3.0 \times 10^{+1}\right)\end{array}$ & $\begin{array}{c}1.4 \times 10^{-2}, n=18 \\
\left(1.6 \times 10^{-3}-1.4 \times 10^{-1}\right)\end{array}$ & This study \\
\hline Fruit vegetables & & $1.0 \times 10^{-1} n=1$ & {$[1]$} \\
\hline Legumes & $\begin{array}{c}2.9 \times 10^{-1}, n=7 \\
\left(2.0 \times 10^{-2}-1.6 \times 10^{0}\right)\end{array}$ & $\begin{array}{c}4.7 \times 10^{-3}, n=7 \\
\left(6.3 \times 10^{-4}-4.2 \times 10^{-2}\right)\end{array}$ & This study \\
\hline Legumes & & $\begin{array}{c}8.5 \times 10^{-3}, n=23 \\
\left(2.0 \times 10^{-4}-1.4 \times 10^{-1}\right)\end{array}$ & {$[1]$} \\
\hline Wheat and barley & $\begin{array}{c}1.6 \times 10^{-1}, n=9 \\
\left(3.1 \times 10^{-2}-5.7 \times 10^{-1}\right)\end{array}$ & $\begin{array}{c}4.9 \times 10^{-3}, n=9 \\
\left(5.1 \times 10^{-4}-3.0 \times 10^{-2}\right)\end{array}$ & This study \\
\hline Cereals & & $\begin{array}{c}6.3 \times 10^{-4}, n=13 \\
\left(1.0 \times 10^{-4}-1.1 \times 10^{-2}\right)\end{array}$ & [1] \\
\hline Brown rice & $\begin{array}{c}2.0 \times 10^{-1}, n=63 \\
\left(1.4 \times 10^{-2}-1.3 \times 10^{0}\right)\end{array}$ & $\begin{array}{c}3.9 \times 10^{-3}, n=59 \\
\left(4.5 \times 10^{-4}-1.8 \times 10^{-2}\right)\end{array}$ & This study \\
\hline Brown rice & & $\begin{array}{c}3.8 \times 10^{-3}, n=8 \\
\left(1.1 \times 10^{-3}-7.6 \times 10^{-3}\right)\end{array}$ & {$[1]$} \\
\hline Bran & $\begin{array}{c}9.9 \times 10^{-1}, n=63 \\
\left(8.9 \times 10^{-2}-6.4 \times 10^{0}\right)\end{array}$ & $\begin{array}{c}3.1 \times 10^{-2}, n=63 \\
\left(3.3 \times 10^{-3}-1.6 \times 10^{-1}\right)\end{array}$ & This study \\
\hline White rice & $\begin{array}{c}1.5 \times 10^{-1}, n=63 \\
\left(1.5 \times 10^{-2}-1.0 \times 10^{0}\right)\end{array}$ & $\begin{array}{c}2.1 \times 10^{-3}, n=45 \\
\left(3.5 \times 10^{-4}-4.9 \times 10^{-3}\right)\end{array}$ & This study \\
\hline
\end{tabular}

been clarified yet so that the effect of direct deposition is necessary to be considered for these TF differences between $\mathrm{Br}$ and I. Moreover, we previously found that $\mathrm{Br}$ was more mobile than I in agricultural soils [11], which would also cause big TF differences between $\mathrm{Br}$ and $\mathrm{I}$.

Rice grains (brown rice) can be separated into white rice and bran parts, and consumption of the former is much higher. Thus, we measured TFs of these parts separately. The results are also listed in Table 2. The GM of TFs of $\mathrm{Br}$ in bran was 7 times higher than that in white rice, while GM of TFs of I in bran was 14 times higher than that in white rice. Tsukada et al. [8] reported that TF for rice bran was 18 times higher than that of white rice, which was similar to the value of the present study. The observed variations could be due to chemical behavior differences between $\mathrm{Br}$ and $\mathrm{I}$ in rice plants. However, a further study is needed to learn the chemical behaviors of halogens in agricultural plants, especially in their edible parts.

\section{Conclusions}

Transfer factors of I for several crop groups were reported. We checked the soil group dependency of I and $\mathrm{Br}$ concentrations in crops using cereals (wheat, barley and brown rice) and observed no statistical differences, but rather to 
agricultural uses and/or crop species. The GMs of TFs of I for eight crop groups ranged from $3.9 \times 10^{-3}$ to $1.4 \times 10^{-2}$, which are relatively narrow ranges compared to TFs of other radionuclides/elements [1]. Thus, as Sheppard et al. [3] reported, these data could be combined to get a generic TF value for foods. However, each group has specifically different TF ranges and GMs, so if possible, different values should be used for more precise dose estimations for ${ }^{129} \mathrm{I}$.

Acknowledgment. The authors thank to Dr. S. Yamasaki, Tohoku University for his help in total I determination in soil samples. This work has been partially supported by the Agency for Natural Resources and Energy, the Ministry of Economy, Trade and Industry (METI), Japan.

\section{References}

1. International Atomic Energy Agency, Quantification of radionuclide transfer in terrestrial and freshwater environments for radiological assessments. Technical Document Series No. 1616, IAEA, Vienna (2009).

2. Sheppard, S. C., Sheppard, M. I., Tait. J.C., Sanipelli, B. L.: Revision and meta-analysis of selected biosphere parameter values for chlorine, iodine, neptunium, radium, radon and uranium. J. Environ. Radioactiv. 89, 115-137 (2006).

3. Ban-nai, T., Muramatsu, Y.: Transfer factors of radioiodine from volcanis-ash soil (Andosol) to crops. J. Radiat. Res. 44, 23-30 (2003).
4. Kashparov, V., Colle, C., Zvarich, S., Yoschenko, V., Levchuk, S., Lundin, S.: Soil-to-plant halogen transfer studies. 1. Root uptake of radioiodine by plants. J. Environ. Radioactiv. 79, 187-204 (2005).

5. Takagi, H., Kimura, T., Kobayashi, H., Iwashima, K., Yamagata, N.: Hokenbutsuri (Jpn. J. Health Phys.) 20, 251-257 (1985) [abstract in English].

6. Yuita, K., Nobusawa, T., Shibuya, M., Aso, S.: Iodine, bromine and chlorine contetns in soils and plants of Japan. 1. Iodine, bromine and chlorine contetns in soils and plants of the basin of the Miomote River. Soil. Sci. Plant Nutr. 28, 315-336 (1982).

7. Tsukada, H., Nakamura, Y.: Transfer factors of 31 elements in several agricultural plants collected from 150 fram fields in Aomori, Japan. J. Radioanal. Nucl. Chem. 236, 123-131 (1998).

8. Tsukada, H., Takeda, A., Tagami, K., Uchida, S.: Uptake and distributon of iodine in rice plants. J. Environ. Qual. 37, 2243-2247 (2008).

9. FAO/UNESCO: Soil Map of he World. Revised legent. World Soil Resources Report 60. FAO Rome (1990).

10. Tagami, K., Uchida, S., Hirai, I., Tsukada, H., Takeda, H.: Determination of chlorine, bromine and iodine in plant samples by inductively coupled plasma-mass spectrometry after leaching with tetramethyl ammonium hydroxie under a mild temperature condition. Anal. Chim. Acta 570, 88-92 (2006).

11. Tagami, K., Uchida, S., Takeda, A., Yamasaki, S., Tsuchiya, N.: Estimation of plant unavailable iodine concentrations in agricultural fields. Manuscript submitted for publication.

12. Muramatsu, Y., Yoshida, S.: Neutron activation analysis of iodine in soil. J. Radioanal. Nucl. Chem. 169, 73-80 (1993). 